\title{
A SLA-Based Assessment of ELT Textbooks in FL Settings
}

\author{
Xiaofei Tang \\ School of Foreign Languages \\ Wuhan University of Technology \\ Wuhan, China \\ xiao-fei.tang@whut.edu.cn
}

\begin{abstract}
This study evaluates four primary-school ELT textbook series used across mainland China from the perspective of psycholinguistics-based SLA. The textbook evaluation aims to determine whether the sequence of grammatical structures introduced as teaching objectives in the series is compatible with the L2 learning sequence stipulated in Processability Theory (PT) The results show a partial consistency between the sequence of grammatical structures in the series and the PT-based learning path. The sequence of structures in the initial stages follows the developmental trajectory of L2 English, while the pedagogical teaching orders of several structures in the later stages differ from their sequences in PT. This may be associated with the theme-based guidelines adopted in the textbooks. Pedagogical suggestions are also provided in terms of the learners' development readiness and the issue of heterogeneity in L2 classrooms.
\end{abstract}

Keywords-Textbook evaluation; grammar; L2 learning sequence; Processability Theory; EFL

\section{INTRODUCTION}

L2 acquisition cannot occur without some sort of language input, and textbooks serve as one main form of language input for learners especially in a foreign language (FL) context. In Mainland China, learners of L2 English have little or no opportunities to access the target language through natural exposure. Textbooks function as the main source of linguistic exposure to English for L2 learners. They also supplement and facilitate the teacher's instruction, by providing organized lesson plans and information on what kinds of teaching practice can be utilized in the classroom. As the use of textbooks in language classrooms is an almost inevitable component of formal instruction in the settings of English as a FL [1], an evaluation of textbooks for the purpose of more efficient teaching and effective learning is a worthwhile undertaking.

The sequence in which the grammatical structures are taught significantly affects language learning outcomes [2]. An improvement in L2 learning can be achieved only when teaching focuses on the grammatical structures that learners are able to acquire at the time of instruction [2-4]. It would benefit formal instruction to follow the path of learnability - namely, the developmental sequence of L2 acquisition.
To the best of my knowledge, SLA-based approach is not found in English textbooks compiled in mainland China. Therefore, it is a sensible idea to examine four sets of ELT textbooks used in mainland China from a SLA theoretical perspective, focusing on the sequencing of English morphology and key sentence structures. The present textbook assessment seeks to answer the question: whether the sequencing of key grammatical structures introduced as the teaching objectives in the four textbook series is compatible with the sequenced development that the learners go through in acquiring English as a L2.

\section{Pt-BASED L2 ENGLISH DEVELOPMENT}

Processability Theory (PT) [5-6] describes, explains and predicts the universal developmental sequence inherent in L2 acquisition from the perspective of language processing. The underlying logic of PT is that L2 learners at any level of development are able to produce only those grammatical structures which the current state of their language processor can process. The developmental sequence of L2 acquisition is determined by the order in which the necessary processing procedures are available to L2 learners. This theory is based on a number of L1 speech production models [7-8], and is formalized within Lexical-Functional Grammar [9-10].

Based on the hypothesis that the processing procedures developed at one stage are a prerequisite for the following stage, PT predicts a hierarchy of processing procedures in morphological and syntactic development of ESL involving a six-stage model of lemma access, category, noun and verb phrase, sentence, and subordinate clause procedures [5] [11] [12]. This implicational hierarchy of ESL development has been generally supported by a range of empirical studies [5] [6] [13-19]. 
TABLE I PROCESSABILITY HIERARCHY: MORPHOLOGICAL DEVELOPMENT FOR L2 ENGLISH [5] [6]

\begin{tabular}{|c|c|c|c|c|}
\hline Stage & Processing procedure & \multicolumn{2}{|c|}{ Morphology } & Example \\
\hline 5 & S-procedure & \multicolumn{2}{|c|}{ SV agreement $(=3 s g-s)$} & She plays football on Mondays. \\
\hline \multirow[t]{2}{*}{4} & \multirow[t]{2}{*}{ VP-procedure } & \multirow[t]{2}{*}{ tense agreement } & be $+V$-ing & She is watching TV. \\
\hline & & & have + V-ed & I have ordered a new book. \\
\hline 3 & NP-procedure & \multicolumn{2}{|l|}{ NP agreement } & I have ten bananas. \\
\hline \multirow[t]{3}{*}{2} & \multirow[t]{3}{*}{ category procedure } & \multicolumn{2}{|l|}{ plural -s (on nouns) } & They're monkeys. \\
\hline & & \multicolumn{2}{|l|}{ possessive pronoun } & It is your kite. \\
\hline & & \multicolumn{2}{|l|}{ simple past -ed } & I cooked fish. \\
\hline 1 & word/lemma & \multicolumn{2}{|l|}{ single words/formulas } & Many thanks! \\
\hline
\end{tabular}

As Table 1 shows, PT predicts five stages in ESL morphological development. At the first stage, L2 lexical items are stored without any grammatical information, and no processing procedure is involved. L2 learners are only able to produce morphologically invariant forms (chunks or nonanalysed material) such as single words (e.g., here) or formulaic expressions (e.g., many thanks).

At the second stage - the category procedure, L2 learners are able to identify the categories of lexical items such as nouns or verbs, but are unable to exchange grammatical information between each lexical item in the phrase or sentence structure. For L2 English, no less than three lexical morphemes are hypothesized to emerge at this stage. Plural $-S$ on nouns describes the lexical nominal plural marking $-S$ on nouns. Simple past -ed refers to the regular past tense marker -ed. Possessive pronoun refers to possessive determiner for adjectives.

At the third stage, once the noun-phrasal procedure has been developed for the L2, diacritic features can be stored, exchanged and unified between the head of a noun phrase (NP) and its modifier. Grammatical information is therefore required to be exchanged within the NP to ensure that the diacritic features of words in the phrase are unified. PT hypothesizes the

TABLE II PROCESSABILITY HIERARCHY: SYNTACTIC DEVELOPMENT FOR L2 ENGLISH [5] [6]

\begin{tabular}{|c|c|c|c|}
\hline Stage & Processing procedure & Syntax & Example \\
\hline 6 & S'-procedure & Cancel inversion & I wonder why he sold that car. \\
\hline \multirow[t]{2}{*}{5} & \multirow[t]{2}{*}{ S-procedure } & Do-2nd & What do you do on Sundays? \\
\hline & & Aux-2nd & Why are you laughing? \\
\hline \multirow[t]{2}{*}{4} & \multirow[t]{2}{*}{ VP-procedure } & Yes/No inversion & Can you speak English? \\
\hline & & Copula inversion & Are you here? \\
\hline \multirow[t]{2}{*}{3} & \multirow[t]{2}{*}{ NP-procedure } & ADV-fronting & Later she could read. \\
\hline & & Do-fronting & Do you like meat? \\
\hline 2 & category procedure & Canonical word order $\mathrm{SV}(\mathrm{O})$ & I like football. \\
\hline 1 & word/lemma & single words/formulas & How are you? \\
\hline
\end{tabular}

phrasal plural marking $-s$ (to achieve $N P$ agreement) to emerge at this stage.

The fourth stage is the verb-phrasal procedure stage, which requires interphrasal agreement-exchanging grammatical information within a verb phrase (VP). The structure hypothesized to emerge at this stage of the interlanguage of L2 learners is the VP composed by the auxiliaries (AUX) and their lexical verbs. To produce this structure, L2 learners need to learn to choose the AUX according to a range of temporal, aspectual or modal motivations (be, have, modal), and then unify these features with the corresponding ones in the lexical verbs ( $V$-ing, $V$-en, $V$ ).

The next stage is the S-procedure stage. The activation of the S-procedure requires interphrasal agreement across different phrases - the subject (SUBJ) and the lexical verb (V)—within a sentence. As PT postulates, L2 English learners can produce the morphological structure known as the $3^{\text {rd }}$ person singular marking $-\mathrm{s}$ in the simple present context, once they are capable of unifying the SUBJ feature information in the $\mathrm{NP}_{\text {SUBJ }}\left(\mathrm{PERSON}=3^{\text {rd }}\right.$; NUMBER=SINGULAR) with the associated $\mathrm{V}$ feature information (TENSE=PRESENT; SUBJ PERSON=3 ${ }^{\text {rd; }}$ SUBJ NUMBER=SINGULAR). 


\section{TEXTBOOK ANALYSIS}

As Table 2 presents, there are six stages predicted in ESL syntactic development. At the first stage, L2 learners have not developed any language-specific procedures, and thus are unable to access any syntactic information. They can only produce single constituents that only require the activation of lemma access, such as How are you? or No.

At the second stage, L2 learners can activate the category procedure, and start to distinguish between verbal elements and nominal elements. They are able to organize their utterances based on the canonical order found in the input from the target language-English. For English syntax, the canonical word order is the subject-verb-object (SVO) structure. At this stage, L2 learners of English can map conceptual structures onto linguistic form. Thus, canonical word order SVO is hypothesized to emerge at this stage of L2 syntactic development.

Next, L2 learners can enter the third stage-the NPprocedure. At this stage, learners are able to place nonarguments (e.g., adjuncts) at the initial position of a canonical word sentence. The syntactic phenomenon known as $A D V$ fronting is hypothesized to emerge by allowing adjuncts such as time or place circumstantial adverbials to appear in the initial position. L2 learners can also produce structures such as Do you like meat? by placing the auxiliary do in the initial position of the canonical order SVO (you like meat). This syntactic phenomenon is called Do-fronting.

At the fourth stage, L2 learners can activate the VPprocedure. They can produce syntactic phenomena such as Yes/No inversion and Copula inversion in non-canonical sequences, by assigning focal function to the auxiliary or copula verb to mark the whole sentence as a question. This results in the inversion between the subject and the auxiliary (or copula).

At the fifth stage, L2 learners can activate the S-procedure and fully differentiate the topic from the subject. They are assumed to be able to implement the procedure of inversion, namely, placing the auxiliary or copula before the subject. Therefore, learners are hypothesized to become able to produce questions such as What does she do? or What did she $d o$ ? by using the morphological form of $d o$ (e.g., does, did).

Once L2 learners have developed all the previous processing resources, they are able to get to the sixth stage and activate the S'-procedure. The activation of this procedure requires the exchange of information between the main clause and the subordinate clause. The learners are assumed to be able to produce indirect questions by allowing interclausal agreement between the verbs in the main clause and the subordinate clause. This syntactic phenomenon is called cancel inversion in the processability hierarchy of L2 syntactic development.

The processability hierarchy of L2 English grammar proposed in PT provides an understanding of how an English learner develops L2 grammar from basic levels to intermediate and high levels. This understanding enables us to focus on the learner's level of ability and to optimize English teaching including textbook and syllabus design.

\section{A. The Selected Textbooks}

The present study evaluates four English textbook series (28 volumes in total) that are currently used in many primary schools in mainland China. They are New Standard English (eight volumes) [20], People's Education Press (PEP) English (eight volumes) [21], Super Kids (four volumes) [22], and Join in (eight volumes) [23]. The four textbook series were selected on the basis of three criteria. First, all of them are officially approved by the Ministry of Education of China for the teaching of English in primary schools from Grade 3 to Grade 6 . Second, they are published by two of the largest educational publishing companies in China-the People's Education Press, and the Foreign Language Teaching and Research Press - and used widely in schools throughout China. Third, they contain explicit syllabi of grammatical structures and vocabulary. As pointed out in the preface to each textbook series, while they focus on the communicative aspect of language and specific cultural contexts, they require mastery of certain grammatical structures and vocabulary to meet the communicative needs of students.

\section{B. The Procedure of Analysis}

The textbook analysis was carried out in three steps. The first step was documenting the focal grammatical items that were introduced as the teaching objectives in the textbooks. Overviews of the focal grammar were provided at the start of each textbook or at the start of individual units in a volume.

The second step was analysing and defining the specific grammatical structures contained in the listed focal items, using grammatical terminology (such as morpheme) and grammatical patterns (such as word order rules). Except for New Standard English, none of the textbook series presented the focal grammar in an explicit way. The majority of the focal items listed in PEP English, Super Kids, and Join in were exemplars of grammatical structures; there was no metalinguistic statement of the rules that were being taught. Thus, an explicit grammatical description was needed to provide a clear understanding of what specific grammatical structures were contained in the listed items.

The third step was tagging and grouping the focal grammatical structures introduced in the textbooks according to the morphological and syntactic categories outlined in the processability hierarchy for L2 English as stipulated in PT (cf. Table 1 and Table 2). The aim of this step was marking where in the textbooks the grammatical structures introduced as teaching objectives occur, and comparing their ordering with the sequence of the corresponding items in the processability hierarchy for L2 English. A distinction was made between the initial occurrence of a structure defined as a teaching objective (a grammatical focus) and incidental later occurrences. Since this study is only concerned with the order of introduction (i.e., the sequencing) of the structures that are teaching objectives, and not with the number of times the structures reoccur in the textbooks, the initial occurrence of the structures that are grammatical foci is our main preoccupation. 


\section{RESUlTS}

On the positive side, the results show that the grammatical sequencing in these four textbook series is partially compatible with the learning sequence as stipulated in PT. For all four textbook series, the morpho-syntactic structures at Stages 1 and 2 are graded in accordance with the hypothesized learning sequence [5] [6]. Despite this, the ordering of the grammatical structures at the later stages slightly differs among the four sets of textbooks and within the areas of morphology and syntax.

In the area of morphology, Super Kids has shown the highest consistency with the learning sequence as stipulated in PT. The other morphological items taught as teaching objectives are introduced in an order that is processable and learnable for students, with the only exception of the VP morpheme 'V-ing' (Stage 4) which is taught in a premature manner. 'V-ing' appears before 'phrasal plural -s' (Stage 3) in the whole textbook series; this does not agree with the PT's hypothesis that the learner can acquire the VP procedural skills only when they have developed all the previous NP procedural skills.

PEP English and Join in have been found to achieve a similar pedagogical teaching order of the morphological items. The morphological items located at the first two stages are taught as grammatical foci in line with the PT-based learning sequence. The pupils are required to begin with the single words or invariant forms; subsequently, they need to develop the category procedural skills (the SVO structure). However, the instruction of 'phrasal plural $-\mathrm{s}$ ' is not presented in a learnable way. It is taught as an instructional focus either before (in PEP English) or simultaneously with (in Join in) the lexical morphemes. Such pedagogical teaching orders are not consistent with the PT's hypothesis that the category procedure is a necessary prerequisite for the NP procedure. The instruction of Stage 4 morphemes ' $V$-ing' and ' $V$-en' are learnable for the pupils, since the two sets of textbooks follow the L2 sequenced development, namely, the learner has to develop the NP procedural skills before he or she moves to the VP procedure stage. Nevertheless, ' $3{ }^{\text {rd }} \mathrm{ps} \mathrm{sg}-\mathrm{s}$ ' is conversely instructed as a teaching objective before the VP morphemes in these two textbook series. This violates the sequenced development of L2 processing skills, namely, the learner is not able to acquire the S-procedural skills before he or she has developed the VP procedural skills.

New Standard English presents a partial agreement with PT' predictions and does not coordinate the ordering of the morphological items at Stages 4-5 with learnability in an effective way; but at least, the morphological items at the initial three stages are ordered in accordance with the hypothesized sequencing. The pedagogical teaching sequence in this textbook series shows that: at first the pupils only need to learn invariant forms, and then they are expected to progress to the category procedure stage (lexical morphemes), and afterwards they have to acquire the NP procedural skills ('phrasal plural $-\mathrm{s}$ '). However, the instruction of ' $\mathrm{V}$-ing' and ' $3^{\text {rd }}$ ps $\mathrm{sg}-\mathrm{s}$ ' is not presented in a learnable manner. They precede their prior-stage morphemes in the textbook series. The pupils cannot acquire these two morphemes due to that they have not developed all the previous processing resources (the NP procedure and the VP procedure) at that point.

The situation in the area of syntax seems less complex. The ordering of the syntactic structures taught as teaching objectives is highly similar among these four sets of textbooks. Overall, except for 'copula inversion' (Stage 4) which is taught before the Stage 3 word orders, the other syntactic features under investigation are ordered in line with the PT-based processability hierarchy. For these four textbook series, the students are required to start with some formulaic structures such as how are you?; later, they are expected to learn the SVO structure through using the category procedure. After developing all the previous processing skills, the students need to acquire the NP procedural skills ('ADV-fronting' and 'dofronting'). However, 'copula inversion' is taught too early in the whole series. The teaching order that the VP procedural skills are developed prior to the NP procedural skills goes against the PT-based learning sequence. The instruction of ' $\mathrm{do}-2^{\text {nd }}$ ' and 'AUX-2 ' $^{\text {nd }}$ ' is considered learnable in these four sets of textbooks, since the students are required to acquire the S-procedural skills after they have developed the VP procedural skills.

\section{LEARNABILITY AND THE SEQUENCE OF GRAMMAR}

From a processability perspective, L2 learners at any level of development are able to produce only those grammatical structures which the current state of their language processing procedures can process [5]. That is, L2 learners are able to learn the structures only when they are developmentally ready to process them. Being 'ready' refers to that the learners have developed the L2 processing procedures required for the acquisition of a grammatical structure situated at the next stage. Here, the key point of learnability is the learners' developmental readiness.

Applied to this textbook evaluation, the sequencing of the morpho-syntactic structures at Stages 1 and 2 in all four sets of textbooks is in full agreement with the learners' developmental readiness. That is, before teaching a grammatical structure such as 'canonical word order SV(O)', which is situated at the category procedure stage (Stage 2), single words or formulaic expressions that are acquired at the lemma access stage (Stage 1) are taught as obligatory learning items in the textbooks. This finding indicates that the authors of these four textbook series have taken into account the learners' developmental readiness in their sequencing of structures at the initial two stages. They have perceived single words or formulaic expressions such as 'How are you?' as less complex items than a canonical word order SVO such as 'I like you'. In other words, since the word order SVO is considered more difficult for L2 students, this structure is introduced as a grammatical focus after formulaic expressions, which are considered less difficult to learn.

However, our findings also reveal that the ordering of several grammatical structures in the four textbook series is different compared to the L2 learning sequence as stipulated in PT. In all four sets of textbooks, there is only one syntactic structure ('copula inversion') taught in a premature manner; two of them present two morphological structures (either 'phrasal plural $-s$ ' or ' 3 rd $p s$ sg $-s$ ') in a deviant pedagogical 
teaching sequence, whereas two of them present one morphological structure ('V-ing') in a deviant teaching order. These forms are introduced as grammatical foci before the structures at their previous stages have been presented. The findings imply that the authors of the four series may consider these four structures less difficult for L2 students and thus these forms are taught earlier than others. However, from a processability perspective, the early instruction of these four structures in the textbooks does not take into consideration L2 learners' developmental readiness.

\section{IMPLICATION OF PREMATURE INSTRUCTION}

The selection and sequence of grammatical structures may be related to the arrangement of themes and relevant functions in the analysed textbook series. It seems that, in these textbooks, the concern with usefulness of a grammatical form in a given context takes precedence over learnability considerations. The premature teaching of structures that are not processable and learnable at a given point may result in a possible negative consequence for a learner's acquisition process.

One possible negative consequence is that students probably avoid or omit the use of the structures they have already acquired at the earlier developmental stages. For example, Pienemann [24] [25] conducted a teaching experiment in which he observed the acquisition by L2 learners of four German word order rules-canonical order (SVO), adverb preposing (ADV), verb separation (SEP), and inversion (INV). These word order rules were hypothesized to emerge at different stages of the L2 German acquisition process: Stage X (SVO), Stage $\mathrm{X}+1$ (ADV), Stage $\mathrm{X}+2$ (SEP), Stage $\mathrm{X}+3$ (INV). Two of the informants were at Stage $\mathrm{X}+1$ (ADV). After the untimely introduction of the structure INV, which should normally occur at Stage $\mathrm{X}+3$, these two informants were found to reduce their frequency of use of the structure ADV by $75 \%$ [25]. When they realised that they were not able to process INV, they attempted to avoid the use of this non-learnable structure and stopped using ADV as well. Such an 'avoidance' or 'omission'-strategy does not contribute to facilitating the acquisition process, but confines the expressiveness of the learner's language [25]. A similar finding was revealed in Lightbown's [26-28] empirical research on L2 English acquisition of adolescent learners who were primarily exposed to classroom input of English. The L2 learners were found to give up using some structures they had learned and replace them with less complex structures such as the use of progressive -ing [28].

\section{How SHOULD We SEQUENCE GRAMMAR?}

How can we, in a feasible manner, sequence grammatical input in textbooks according to the developmental path of L2 acquisition? Here are two suggestions which may be considered in future textbook compilation.

First, the grammatical items integrated in the textbooks, including exercises and tasks, should be subdivided into two categories: the obligatory structures and the optional structures. The obligatory structures refer to the learning objectives required to be learned and produced by students. The optional structures refer to those features that are not required for production but that appear as structural consequences of the structures that are obligatory to achieve the communicative needs within the textbook theme (or topics).

Second, the grammatical items that are specified as the obligatory structures should be selected and graded in accordance with the L2 acquisition process as stipulated in PT: (1) a structure at an earlier stage should be introduced before a structure at a later stage; and (2) structures at the intermediate or high levels, such as $3^{r d} p s s g$. $-s$, should not be introduced as obligatory structures in the initial volumes of a textbook series or the beginning units of a textbook.

\section{CONCLUSION}

This study reports on an acquisition-based evaluation of four English textbook series for primary school education in China. Under the methodological guidance of PT, this evaluation has examined that the sequencing of grammatical structures in these four textbook series is partially compatible with the developmental sequence of the L2 English acquisition process.

This study has implications for ESL pedagogy. The study reveals current trends in English textbook compilation in China, where reliance on a theme-based approach means that textbook authors primarily concern themselves with the usefulness of grammatical forms within a given theme, rather than with learnability considerations. The related findings may draw more attention to the issue of how to balance communicative needs and the grading of grammar in L2 teaching. The proposed suggestions may serve as a reference for the design of grammatical syllabi in a theme-based textbook for a L2 communicative classroom.

A limitation related to the research scope needs to be acknowledged. Issues related to grammatical presentation and general input provided by textbooks such as exercises remain a matter for further investigation. Future research may incorporate other SLA approaches such as input frequency or input processing into the PT-based approach.

\section{REFERENCES}

[1] Hutchinson, T. and E. Torres. 1994. The textbook as agent of change. ELT Journal 48(4), 315-328.

[2] Mansouri, F. and L. Duffy. 2005. The pedagogic effectiveness of developmental readiness in ESL grammar instruction. Australian Review of Applied Linguistics 28(1), 81-99.

[3] Ellis, R. 1989. Are classroom and naturalistic acquisition the same? A study of the classroom acquisition of German word order rules. Studies in Second Language Acquisition 11(3), 303-328.

[4] Pienemann, M. 1984. Psychological constraints on the teachability of languages. Studies in Second Language Acquisition 6(2), 186-214.

[5] Pienemann, M. 1998. Language processing and second language development: Processability Theory. Philadelphia: John Benjamins Publishing Company.

[6] Pienemann, M. 2005. Cross-linguistic aspects of Processability Theory. Amsterdam: John Benjamins Publishing Company.

[7] Kempen, G. and E. Hoenkamp. 1987. An incremental procedural grammar for sentence formulation. Cognitive Science 11(2), 201-258.

[8] Levelt, W. J. M. 1989. Speaking: From intention to articulation. Cambridge, Mass: MIT Press.

[9] Bresnan, J. 2001. Lexical-functional syntax. Oxford: Blackwell. 
[10] Kaplan, R. and J. Bresnan. 1982. Lexical-Functional Grammar: A formal system for grammatical representation. In J. Bresnan, ed., The mental representation of grammatical relations. Cambridge, MA: The MIT Press. 173-281.

[11] Bettoni, C. and B. Di Biase. 2015. Grammatical development in second languages: Exploring the boundaries of processability theory. European Second Language Acquisition.

[12] Pienemann, M., B. Di Biase and S. Kawaguchi. 2005. Extending Processability Theory. In M. Pienemann, ed., Cross-linguistic aspects of Processability Theory. Amsterdam: John Benjamins Publishing Company. 199-251.

[13] Charters, H., L. Jansen and L. Dao. 2012. Think of a number: learning to make nouns plural in second language acquisition. Association Francaise de Linguistique Cognitive 8.

[14] Dyson, B. 2009. Processability Theory and the role of morphology in ESL development: A longitudinal study. Second Language Research 25, 355-376.

[15] Dyson, B. and G. Håkansson. 2017. Understanding second language processing: A focus on Processability Theory. Philadelphia: John Benjamins Publishing Company.

[16] Keßler, J.-U. 2007. Assessing EFL-development online: A feasibility study of Rapid Profile. In F. Mansouri, ed., Bilingualism and theorydriven second language acquisition research. Newcastle upon Tyne: Cambridge Scholars Press. 119-143.

[17] Lenzing, A. 2008. Teachability and learnability: An analysis of primary school textbooks. In J.-U. Keßler, ed., Processability approaches to second language development and second language learning. Newcastle, UK: Cambridge Scholars Publishing. 221-241.

[18] Pienemann, M. and J.-U. Keßler. 2011. Studying Processability Theory: An introductory textbook. Philadelphia: John Benjamins Publishing Company.

[19] Zipser, K. 2012. Processability theory and pedagogical progression in an Italian textbook. Linguistica 52(1), 55-68.

[20] Chen, L. and P. Ellis. 2012. New standard English. Beijing: Foreign Language Teaching and Research Press.

[21] Wu, X. 2012. People's Education Press English. Beijing: People's Education Press.

[22] Liu, D., A. Krause and G. Cossu. 2012. Super kids (1 ${ }^{\text {st }}$ ed.). Beijing: People Education Press \& Pearson Longman Publishing Group.

[23] Zhang, S. 2014. Join in. Beijing: Foreign Language Teaching and Research Press.

[24] Pienemann, M. 1986. The effect of instruction on learners' orientation in L2 acquisition. In A. Ramat, ed., L'apprendimiento non guidato di una seconda lingua. Bologna: Mulino. 307-326.

[25] Pienemann, M. 1989. Is language teachable? Psycholinguistic experiments and hypotheses. Applied Linguistics 10(1), 52-79.

[26] Lightbown, P. M. 1982. Classroom language as input to second language acquisition. Paper presented at the Second European-North American Workshop on Second Language Acquisition Research, Gohrde, West Germany, August.

[27] Lightbown, P. M. 1983. Exploring relationships between developmental and instructional sequences in L2 acquisition. In H. W. Seliger and M. $\mathrm{H}$. Long, eds., Classroom-oriented research in language acquisition. Rowley MA: Newbury House. 217-243.

[28] Lightbown, P. M. 1985. Great expectations: Second language acquisition research and classroom teaching. Applied Linguistics 6 (2), 74-90. 